\title{
Psychometric properties of a French version of a Dutch scale for assessing breast and body image $(B B I S)$ in healthy women
}

Noémie Resseguier ${ }^{1,2,3}$, Catherine Noguès ${ }^{4,5}$, Roch Giorgi ${ }^{1,2,3}$ and Claire Julian-Reynier ${ }^{1,2,3,6^{*}}$

\begin{abstract}
Background: Genetic testing among women for BRCA1/2 mutation can have various psychological effects, such as those focusing on body image. The aim of this study was to examine the psychometric properties of a generic scale assessing breast and body image (BBIS) in healthy women tested for BRCA1/2 mutations.

Methods: A Dutch body image scale focusing on both general and breast-related body image was translated into French. It was presented to a French cohort of female cancer-free BRCA1/2 mutation carriers and non-carriers $(\mathrm{N}=568)$. The psychometric properties of the scale were studied by assessing its dimensional and factorial structure, internal consistency, construct-related validity, and external validity.

Results: The scale was found to be a satisfactory psychometric tool for assessing both body image and breast image. The three main dimensions which emerged were classified under the headings "values attached to body image", "satisfaction with body image and perceived attractiveness", and "satisfaction with breasts". The BBIS scores were not significantly associated with the participants' socio-demographic characteristics or their BRCA1/2 mutation carrier status, but significant associations were observed between these scores and the women's medical and behavioural characteristics.
\end{abstract}

Conclusions: The BBIS is a generic tool which can be used to assess body image in either affected or unaffected women. The scale will have to be administered to other populations in order to confirm its validity.

Keywords: Body image, Women, Breasts, BRCA1/2 mutation, Psychometric properties

\section{Background}

Body image is a complex, multidimensional concept at the crossroads between various fields. It involves people's self-perceptions and their attitudes (i.e., their thoughts, feelings, and behavior) towards their body, and suitable tools are required for assessing it [1-3]. As suggested in a previous cognitive-behavioral model of body image, it includes (i) body image evaluation which refers to satisfaction or dissatisfaction with one's body, including evaluative beliefs about it, and (ii) body image investment which refers to the cognitive, behavioral, and emotional importance persons attach to their appearance [2]. Body image assessment has been described as stemming

\footnotetext{
* Correspondence: claire.julian-reynier@inserm.fr

'INSERM, U912, SESSTIM, Marseille, France

${ }^{2}$ IRD, U912, SESSTIM, Marseille, France

Full list of author information is available at the end of the article
}

from the degree of discrepancy or congruence between self-perceived physical characteristics and personally valued ideals of physical appearance [4]. Research on body image focused initially on female populations. Since body image is experienced differently among men and women [5,6], scales assessing body image should be gender-related. In women, body image relates to femininity, and the latter aspect should also be assessed when measuring women's body image $[7,8]$; since the breasts are one of the main symbols of femininity, body image scales should include how they are perceived, whatever the context involved (clinical populations with and without breast disease and general populations).

In clinical practice, body image is a useful concept for assessing the effectiveness of surgical and medical interventions (e.g., plastic surgery $[9,10]$, dieting for obesity [11-13], and treatment of eating disorders [14,15]). 
Physical diseases and injuries and psychiatric disorders and their treatment can completely change the functional integrity of the body and its appearance, which in turn can greatly affect patients' body image, their psychosocial wellbeing and their quality of life. In order to assess body image in clinical populations, several scales have been developed for use in clinical practice and research and validated on these particular populations [16-18]. However, these scales can be used only on the specific populations for which they were designed, to assess the effects of a disease and its treatment on the patients' body image.

The factors involved in the case of healthy subjects are likely to differ completely from those contributing to the body image of affected patients [3,19,20]. Questions about the effects of disease and its treatment on respondents' body image are no longer relevant here, and many of the previously developed scales are unsuitable for use in this context. Greater attention should be paid to developing generic body image scales which could be used on healthy populations. Generic scales would be particularly useful in the context of longitudinal studies, as they could be used to repeat the measurements over a period of time, even if the subjects' condition has evolved. Items relating to highly specific situations could be added to these generic scales when necessary in order to obtain both a generic body image and a specific body image, depending on the framework of the survey.

Halfway between clinical and healthy populations, there exists a group consisting of people at risk, who may possibly contract a disease one day or may have to make prophylactic decisions [21-23]. A typical example of populations of this kind is that consisting of carriers of deleterious genetic mutations, such as $B R C A 1 / 2 \mathrm{mu}-$ tations. Women with a $B R C A 1 / 2$ mutation have up to an $87 \%$ lifetime risk of developing breast cancer and a $15-60 \%$ lifetime risk of developing ovarian cancer $[24,25]$. Being a carrier of a BRCA1/2 mutation has psychosocial effects, including those focusing on how people view themselves such as body image [26]. In addition, some of the women with a high genetic risk of developing cancer undergo prophylactic surgery (risk-reducing mastectomy or oophorectomy), which is liable to have negative effects on these patients' body image $[22,23]$.

A scale was previously developed by Lodder et al. for assessing body image in unaffected women carriers of a BRCA1/2 mutation [22]. In this study, Lodder established that mutation carriers who underwent prophylactic mastectomy (with reconstruction) had a poorer breast-related image after one year of follow-up than mutation carriers who had opted for surveillance and non-mutation carriers. But as far as we know, this scale has been used but never validated so far [27]. The aim of the present study was therefore to present this generic body image scale and to study its psychometric properties on unaffected French female BRCA1/2 mutation carriers and non-carriers.

\section{Methods}

\section{Ethics statement}

The informed consent of each participant was obtained at the beginning of the study after explaining the purpose of this study in detail. The study was approved by the French National Commission for Data Protection and Privacy ("Commission Nationale de l'Informatique et des Libertés").

\section{Study population}

In the framework of the ongoing French GENEPSO ("Gene Etude Prospective Sein Ovaire") project managed by the French Cancer Genetic Network, BRCA1/2 mutation carriers were recruited in a routine consultation context at cancer genetic clinics between 2000 and 2006. Non carriers from families where a BRCA1/2 mutation had been identified were included as well as carriers.

Eligible subjects were therefore women aged 18 years or more, who were cancer-free, belonged to a family in which a deleterious predisposing BRCA1/2 mutation had been identified, and were tested for this mutation.

\section{Procedure}

Women included in the cohort filled in a selfadministered questionnaire at the cancer genetic clinic before delivery of the genetic test results (questionnaire $\mathrm{Q}_{\mathrm{DO}}$ ) and a different self-administered questionnaire which was sent to their homes 15 days after delivery of the results (questionnaire $\mathrm{Q}_{\mathrm{D} 15}$ ). If no answer had been received one month after mailing the questionnaire, a reminder and a copy of the questionnaire were sent out. All the completed questionnaires were mailed back to the coordinating centre. The cancer geneticists also completed a questionnaire describing the women's family members and their medical characteristics at inclusion and follow-up.

\section{Instruments}

The questionnaire $\mathrm{Q}_{\mathrm{D} 0}$ focused on the respondents' sociodemographic data (on aspects such as age, marital status and education). The questionnaire $Q_{D 15}$, which focused on their psychological characteristics [27], assessed the respondents' depressive symptoms using the French version of the Center for Epidemiologic Studies Depression Scale (CES-D) [28,29] and their breast and body image. The CES-D scale consists of 20 items giving a total score after giving each item a score of $0 / 1 / 2 / 3$. The overall score was dichotomized using the value of 23 as a cutoff point, as previously 
recommended for identifying French women with high depressive symptoms [28].

At the onset of the study, no questionnaires on body image tailored to the present study population were available and validated in French. We translated the body image scale presented by Lodder et al. in a similar study [22]; it was first translated by two French native speakers who were fluent in Dutch, before being translated back into Dutch by a Dutch native speaker who was fluent in French [30]. To develop this scale, Lodder followed previous recommendations (Hopwood [16,17]) by addressing both the question of general body image and that of breast-related body image. This scale included various aspects which have been said to be important factors contributing to cancer patients' body image [16]: 1) satisfaction with appearance when dressed, 2) feeling feminine, 3) satisfaction with appearance when naked, 4) feeling attractive, and 5) feeling conscious about one's appearance. Three questions were added to obtain a specific breast-related body image scale assessing whether women were satisfied with the way their breasts felt when touching them (two items) and with their appearance (one item). Lastly, two other items were included about the importance attached to physical appearance. We ourselves added an item about the importance attached to the appearance of the breasts (item 2). The complete scale therefore consisted of 11 items translated from Lodder's scale and one item added by ourselves. Among the twelve items on the scale, 10 were positively-worded and two were negatively-worded (reversed coding). A five-point Likert scale ranging from zero to four was used to define the responses in terms of agreement ("Strongly disagree", "Disagree", "Neither agree nor disagree", "Agree", "Strongly agree"). The list of items is presented in Table 1 . We named this scale BBIS, which stands for Breast and Body Image Scale.

\section{Statistical analysis}

The characteristics of the study population were described in the population as a whole and in two subpopulations, defined in terms of whether or not there were missing values in the body image scale. The distribution of these characteristics was compared between these two sub-populations using chi-square tests. Determinants for being an incomplete responder to the BBIS were tested using a multivariate logistic regression model. No variable selection was performed using statistical criteria, and adjusted odds ratios were estimated.

Analyses of the frequency distribution were performed at the item level, including missing values. The following analyses were then performed on complete cases.

Pearson's correlation coefficients between the various items were calculated in order to detect any redundant items.

\begin{tabular}{|c|c|c|}
\hline \multicolumn{3}{|c|}{ French version } \\
\hline $\begin{array}{l}\text { Item } \\
1\end{array}$ & $\begin{array}{l}\text { D'une manière } \\
\text { générale }\end{array}$ & Pour moi, I'apparence physique est importante \\
\hline $\begin{array}{l}\text { Item } \\
2\end{array}$ & & Pour moi, I'apparence des seins est importante \\
\hline $\begin{array}{l}\text { Item } \\
3\end{array}$ & & Je soigne beaucoup mon apparence \\
\hline $\begin{array}{l}\text { Item } \\
4\end{array}$ & $\begin{array}{l}\text { Au cours du } \\
\text { dernier mois }\end{array}$ & $\begin{array}{l}\text { J'étais satisfaite de mon apparence quand } \\
\text { j'étais habillée }\end{array}$ \\
\hline $\begin{array}{l}\text { Item } \\
5\end{array}$ & & Je me sentais très féminine \\
\hline $\begin{array}{l}\text { Item } \\
6\end{array}$ & & J'étais très consciente de mon image \\
\hline $\begin{array}{l}\text { Item } \\
7\end{array}$ & & $\begin{array}{l}\text { J'étais satisfaite de mon apparence quand } \\
\text { j'étais nue }\end{array}$ \\
\hline $\begin{array}{l}\text { Item } \\
8\end{array}$ & & J'avais du mal à me regarder nue (inversé) \\
\hline $\begin{array}{l}\text { Item } \\
9\end{array}$ & & J'avais du mal à toucher ma poitrine (inversé) \\
\hline $\begin{array}{l}\text { Item } \\
10\end{array}$ & & J'étais satisfaite de l'apparence de mes seins \\
\hline $\begin{array}{l}\text { Item } \\
11\end{array}$ & & Mes seins étaient agréables au toucher \\
\hline $\begin{array}{l}\text { Item } \\
12\end{array}$ & & Je me sentais séduisante \\
\hline \multicolumn{3}{|c|}{ English version [22] } \\
\hline $\begin{array}{l}\text { Item } \\
1\end{array}$ & $\begin{array}{l}\text { Generally } \\
\text { speaking }\end{array}$ & I find it important to look good \\
\hline $\begin{array}{l}\text { Item } \\
2\end{array}$ & & I find it important that my breasts look good \\
\hline $\begin{array}{l}\text { Item } \\
3\end{array}$ & & I pay much attention to my appearance \\
\hline $\begin{array}{l}\text { Item } \\
4\end{array}$ & $\begin{array}{l}\text { In the past } \\
\text { month }\end{array}$ & $\begin{array}{l}\text { I was satisfied with my appearance when } \\
\text { dressed }\end{array}$ \\
\hline $\begin{array}{l}\text { Item } \\
5\end{array}$ & & I felt quite feminine \\
\hline $\begin{array}{l}\text { Item } \\
6\end{array}$ & & I felt very conscious about my appearance \\
\hline $\begin{array}{l}\text { Item } \\
7\end{array}$ & & $\begin{array}{l}\text { I was satisfied with my appearance when } \\
\text { undressed }\end{array}$ \\
\hline $\begin{array}{l}\text { Item } \\
8\end{array}$ & & $\begin{array}{l}\text { I had difficulty in looking at my body when } \\
\text { undressed (reverse coding) }\end{array}$ \\
\hline $\begin{array}{l}\text { Item } \\
9\end{array}$ & & $\begin{array}{l}\text { I had difficulty in touching my breasts (reverse } \\
\text { coding) }\end{array}$ \\
\hline $\begin{array}{l}\text { Item } \\
10\end{array}$ & & $\begin{array}{l}\text { I was satisfied with the appearance of my } \\
\text { breasts }\end{array}$ \\
\hline $\begin{array}{l}\text { Item } \\
11\end{array}$ & & My breasts felt pleasant \\
\hline $\begin{array}{l}\text { Item } \\
12\end{array}$ & & I felt attractive \\
\hline
\end{tabular}


The dimensionality of the scale was determined by performing exploratory factor analysis (Principal Component Analysis; PCA). The Scree plot and the Kaiser criterion were used to decide about the appropriateness of the number of factors retrieved. A varimax rotation was then performed in order to estimate the factor loadings, and each item was taken to contribute to the factor corresponding to its highest loading value. As the Kaiser criterion tends to result in the over-extraction of factors, we compared the goodness of fit of the selected model with models including fewer factors. We studied five fit indices [31]: the Normed Fit Index (NFI), the TuckerLewis Index (TLI), the Comparative Fit Index (CFI), the Root Mean Square Error of Approximation and its confidence interval (RMSEA), and the Bayesian Information Criterion (BIC).

Each factor which emerged was used to define a subscale. The score obtained on each sub-scale was calculated by summing the responses to the various items included in the corresponding sub-scale. As an exploratory endpoint, an overall score was also calculated by summing together the scores obtained on the various sub-scales.

The internal consistency was assessed by determining Cronbach's alpha coefficients. Confidence intervals were determined using bootstrapping methods. Pearson's correlation coefficients between the various sub-scales were calculated and compared with Cronbach's $\alpha$ coefficients. If the value of the correlation coefficient was lower than that of the Cronbach's $\alpha$ coefficients, the components were taken to measure other aspects [32]. The construct-related validity was determined by assessing the item convergent validity and the item discriminant validity.

In order to assess the external validity of the scale, we studied the associations existing between the scores obtained on the BBIS and various covariates previously found in the literature to be associated with the body image. Means BBIS scores were compared in terms of these characteristics, using ANOVA tests.

All tests were two-sided, and differences were taken to be significant at $p$-values $<.05$. All analyses were performed using the $\mathrm{R}$ software.

\section{Results}

\section{Study population}

Among the 613 women who were recruited, 45 did not complete the $\mathrm{Q}_{\mathrm{D} 15}$ questionnaire, including one who declared that she did not want to participate in the study any longer. Data were analysed on the 568 women who answered the $\mathrm{Q}_{\mathrm{D} 15}$ questionnaire (245 BRCA1/2 mutation carriers and $323 B R C A 1 / 2$ non carriers). Sociodemographic and medical characteristics of the overall study sample and those of the subsamples of women who had not $(\mathrm{N}=517,91 \%)$ and those who had $(\mathrm{N}=$ 51, 9\%) missing values in the BBIS are given in Table 2. Univariate analysis showed that age, level of education and BMI index classes were significantly associated with the presence of missing values in the BBIS. After systematically adjusting on all the covariates collected in a multivariate logistic regression model, only a high level of education was found to be significantly associated with a lower risk of missing values in the BBIS.

\section{Distribution of the responses to the various items on the scale}

The distributions of the responses of all the participants $(\mathrm{N}=568)$ to the various items in the BBIS are presented in Table 3. The rate of missing values among the items was low (range: $1.6 \%$ - 3.9\%). No floor effect was observed. A ceiling effect was observed in the case of the eighth item (reverse coding) and especially in that of the ninth item (reverse coding). The negative wording of these two items may account for the presence of these different distributions. These distributions were actually not very surprising, since there were only a few possible responses to each question.

\section{Correlations between items on the scale}

The Pearson's correlation coefficients between items are presented in Table 3 (based on fully completed questionnaires, $\mathrm{N}=517$ ). The maximum value of these coefficients was 0.73. A few negative correlations were obtained, but since the coefficients were small in these cases, all the items on the scale could be taken to measure a common concept.

\section{Dimensional structure of the scale}

The three-dimensional representation of the correlation matrix (between items) based on the Principal Component Analysis is presented in Figure 1. Two and three components accounted for $53 \%$ and $62 \%$ of the variance, respectively. In view of the three-dimensional spherical form of presentation, there seem to exist three dimensions on the scale. The scree plot of the eigenvalues indicated that there may be either one or three dimensions on the scale (Figure 2). Based on Kaiser's criterion, a three-factor model was used for the factor analysis.

Loading values based on the factor analysis performed with a three-factor model are presented in Table 4. Items 1,2 and 3 were taken to form the first factor, items 4,5 , $6,7,8$ and 12, the second factor, and items 9,10 and 11 , the third factor. Based on this loading pattern, factor 1 was labelled "values attached to body image" ("ValBI"), factor 2, "satisfaction with body image and perceived attractiveness" ("SatBIPA") and factor 3, "satisfaction with breasts" ("SatBr"). 
Table 2 Socio-demographic and medical characteristics of the overall study sample $(\mathrm{N}=\mathbf{5 6 8})$ and those of the subsamples of women whose responses to the Breast and Body Image Scale (BBIS) were complete $(\mathrm{N}=517)$ and those whose questionnaires had missing values $(\mathrm{N}=\mathbf{5 1})$

\begin{tabular}{|c|c|c|c|c|c|c|c|}
\hline & \multirow{2}{*}{$\begin{array}{l}\text { All women } \\
\text { N (\%) }\end{array}$} & \multirow{2}{*}{$\begin{array}{c}\text { Women with no } \\
\text { MVs in the BBIS N (\%) }\end{array}$} & \multirow{2}{*}{$\begin{array}{c}\text { Women with } \\
\text { MVs in the BBIS N (\%) }\end{array}$} & \multirow{2}{*}{$\begin{array}{l}\text { Univariate analysis } \\
\qquad \text { p-value }^{a}\end{array}$} & \multicolumn{3}{|c|}{ Multivariate analysis } \\
\hline & & & & & $\operatorname{adj} O R^{b}$ & $\mathrm{Cl} 95 \%$ & p-value \\
\hline Age (yrs) & & & & $<0.01$ & & & 0.44 \\
\hline$\leq 30$ & $105(18.5)$ & $102(19.7)$ & $3(5.9)$ & & 0.29 & $0.04-1.27$ & \\
\hline $31-40$ & $205(36.1)$ & $195(37.7)$ & $10(19.6)$ & & 0.62 & $0.22-1.71$ & \\
\hline $41-50$ & $152(26.8)$ & $136(26.3)$ & $16(31.4)$ & & 0.75 & $0.30-1.93$ & \\
\hline$>50$ & $106(18.7)$ & $84(16.2)$ & $22(43.1)$ & & 1 & - & \\
\hline Level of education & & & & $<0.01$ & & & $<0.01$ \\
\hline Less than high school certificate level & $139(24.5)$ & $111(21.5)$ & $28(54.9)$ & & 1 & - & \\
\hline High school certificate & $110(19.4)$ & $103(19.9)$ & $7(13.7)$ & & 0.29 & $0.09-0.80$ & \\
\hline Above high school level certificate & $316(55.6)$ & $301(58.2)$ & $15(29.4)$ & & 0.24 & $0.09-0.60$ & \\
\hline MVs & $3(0.5)$ & $2(0.4)$ & $1(2.0)$ & & & & \\
\hline Living with a partner & & & & 0.22 & & & 0.28 \\
\hline No & $127(22.4)$ & $119(23.0)$ & $8(15.7)$ & & 1 & - & \\
\hline Yes & $426(75.0)$ & $384(74.3)$ & $42(82.4)$ & & 1.79 & $0.65-6.25$ & \\
\hline MVs & $15(2.6)$ & $14(2.7)$ & $1(2.0)$ & & & & \\
\hline Body Mass Index class & & & & 0.02 & & & 0.70 \\
\hline$<18.5$ Underweight & $33(5.8)$ & $30(5.8)$ & $3(5.9)$ & & 1.83 & $0.39-6.26$ & \\
\hline 18.5-24.9 Normal weight & $379(66.7)$ & $354(68.5)$ & $25(49.0)$ & & 1 & - & \\
\hline 25.0-29.9 Overweight & $116(20.4)$ & $97(18.8)$ & $19(37.3)$ & & $1.04^{*}$ & $0.44-{ }^{*} 2.34$ & \\
\hline$\geq 30$ Obesity & $26(4.6)$ & $24(4.6)$ & $2(3.9)$ & & & & \\
\hline MVs & $14(2.5)$ & $12(2.3)$ & $2(3.9)$ & & & & \\
\hline Regular gynecological follow-up & & & & 0.18 & & & 0.61 \\
\hline No & $58(10.2)$ & $50(9.7)$ & $8(15.7)$ & & 1 & - & \\
\hline Yes & $506(89.1)$ & $463(89.6)$ & $43(84.3)$ & & 0.72 & $0.16-2.33$ & \\
\hline MVs & $4(0.7)$ & $4(0.8)$ & $0(0.0)$ & & & & \\
\hline Breast self-examination & & & & 0.75 & & & 0.44 \\
\hline No & $303(53.3)$ & $277(53.6)$ & $26(51.0)$ & & 1 & - & \\
\hline Yes & 257 (45.2) & $233(45.1)$ & $24(47.1)$ & & 0.75 & $0.35-1.57$ & \\
\hline MVs & $8(1.4)$ & $7(1.4)$ & $1(2.0)$ & & & & \\
\hline
\end{tabular}


Table 2 Socio-demographic and medical characteristics of the overall study sample $(\mathbf{N}=\mathbf{5 6 8})$ and those of the subsamples of women whose responses to the Breast and Body Image Scale (BBIS) were complete $(\mathbf{N}=\mathbf{5 1 7})$ and those whose questionnaires had missing values $(\mathrm{N}=\mathbf{5 1})(\mathrm{Continued})$

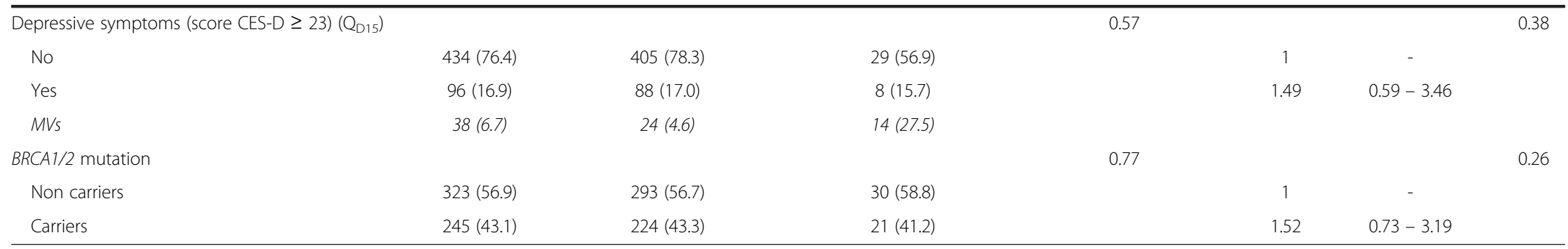

MVs: missing values; CES-D: Center for Epidemiologic Depression Scale; $Q_{D 15}$ : questionnaire filled in 15 days after test result disclosure.

"The body mass index classes "25.5-29.9 Overweight" and " $\geq 30$ Obesity" were pooled to obtain more accurate estimates.

a $\mathrm{p}$-value in univariate tests comparing the distributions of the sociodemographic and medical characteristics according to the status MVs / no MVs in the BBIS.

b Adjusted odds ratio of the excess risk of having missing values in the BBIS. 
Table 3 Matrix of correlations between the various items on the breast and body image scale 15 days after test result disclosure $(\mathrm{N}=517)$, and distribution of the responses to the various items on the questionnaire $(N=568$; bottom of the Table)

\begin{tabular}{|c|c|c|c|c|c|c|c|c|c|c|c|c|}
\hline & 1 & 2 & 3 & 4 & 5 & 6 & 7 & 8 & 9 & 10 & 11 & 12 \\
\hline 1: It's important to look good & 1 & & & & & & & & & & & \\
\hline 2: It's important that breasts look good & 0.59 & 1 & & & & & & & & & & \\
\hline 3: Attention to appearance & 0.55 & 0.40 & 1 & & & & & & & & & \\
\hline 4: Satisfied with appearance when dressed & 0.30 & 0.19 & 0.42 & 1 & & & & & & & & \\
\hline 5: Feeling feminine & 0.28 & 0.23 & 0.45 & 0.73 & 1 & & & & & & & \\
\hline 6: Conscious about one's appearance & 0.23 & 0.22 & 0.36 & 0.38 & 0.49 & 1 & & & & & & \\
\hline 7: Satisfied with one's appearance when undressed & 0.19 & 0.11 & 0.32 & 0.58 & 0.55 & 0.34 & 1 & & & & & \\
\hline 8: Difficulty in looking at one's body when undressed (R) & 0.02 & -0.01 & 0.12 & 0.33 & 0.28 & 0.14 & 0.42 & 1 & & & & \\
\hline 9: Difficulty in touching breasts (R) & -0.03 & -0.01 & -0.03 & 0.09 & 0.12 & 0.12 & 0.10 & 0.29 & 1 & & & \\
\hline 10: Satisfied with appearance of breasts & 0.16 & 0.19 & 0.20 & 0.36 & 0.39 & 0.25 & 0.43 & 0.21 & 0.17 & 1 & & \\
\hline 11: Breasts feel pleasant & 0.19 & 0.23 & 0.23 & 0.32 & 0.37 & 0.27 & 0.32 & 0.22 & 0.29 & 0.53 & 1 & \\
\hline 12: Feeling attractive & 0.27 & 0.23 & 0.35 & 0.60 & 0.63 & 0.37 & 0.60 & 0.41 & 0.21 & 0.52 & 0.54 & 1 \\
\hline Mean score & 3.28 & 3.22 & 2.95 & 2.89 & 2.92 & 2.99 & 2.18 & 3.00 & 3.41 & 2.73 & 2.92 & 2.56 \\
\hline Standard Deviation & 0.83 & 0.90 & 0.90 & 1.00 & 1.01 & 0.96 & 1.21 & 1.21 & 1.13 & 1.15 & 1.02 & 1.03 \\
\hline Median & 3 & 3 & 3 & 3 & 3 & 3 & 2 & 3 & 4 & 3 & 3 & 3 \\
\hline "Strongly disagree": N (\%) & $4(1)$ & $6(1)$ & $6(1)$ & $11(2)$ & $8(1)$ & $10(2)$ & $50(9)$ & $26(5)$ & $27(5)$ & $30(5)$ & $10(2)$ & $13(2)$ \\
\hline "Disagree": N (\%) & $25(4)$ & $30(5)$ & $42(7)$ & $54(10)$ & $58(10)$ & $34(6)$ & $132(23)$ & $55(10)$ & $25(4)$ & $58(10)$ & $35(6)$ & $75(13)$ \\
\hline "Neither agree nor disagree": N (\%) & $38(7)$ & $53(9)$ & $81(14)$ & $82(14)$ & $83(15)$ & $90(16)$ & $119(21)$ & $84(15)$ & $50(9)$ & $106(19)$ & $144(25)$ & $158(28)$ \\
\hline "Agree": N (\%) & $234(41)$ & $216(38)$ & $276(49)$ & $243(43)$ & $229(40)$ & $228(40)$ & $173(30)$ & $115(20)$ & $44(8)$ & $192(34)$ & $159(28)$ & $194(34)$ \\
\hline "Strongly agree": N (\%) & $256(45)$ & $251(44)$ & $154(27)$ & $164(29)$ & $176(31)$ & $184(32)$ & $79(14)$ & $270(47)$ & $404(71)$ & $162(29)$ & $198(35)$ & $106(19)$ \\
\hline Missing value: N (\%) & $11(2)$ & $12(2)$ & $9(2)$ & $14(2)$ & $14(2)$ & $22(4)$ & $15(3)$ & $18(3)$ & $18(3)$ & $20(4)$ & $22(4)$ & $22(4)$ \\
\hline
\end{tabular}




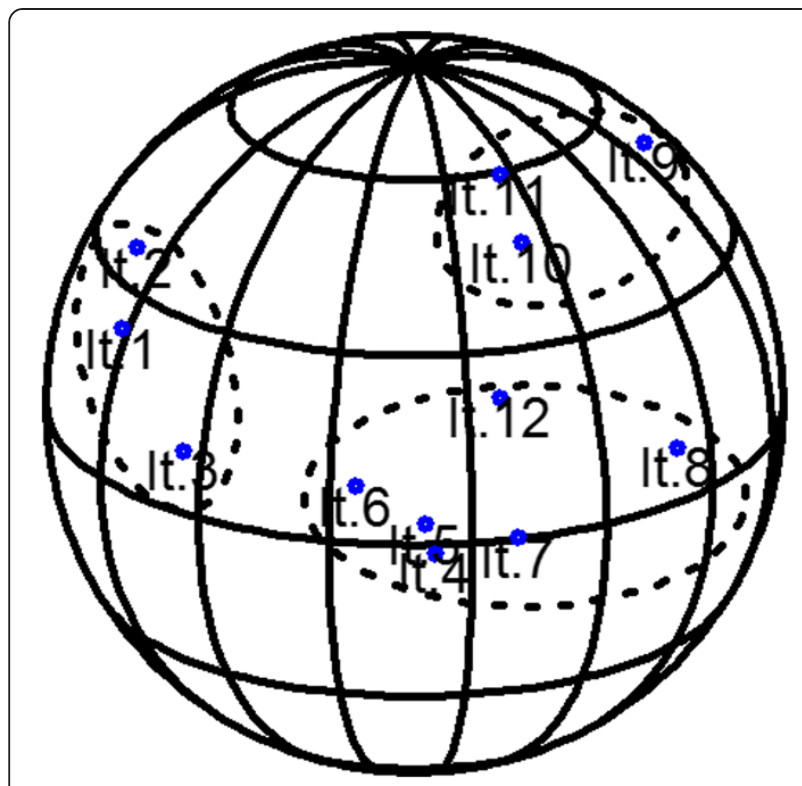

Figure 1 Three-dimensional diagram of the correlation matrix among the various items on the scale $(\mathrm{N}=517)$. All items on the scale could be depicted on the same side of the sphere.

Three decreasingly complex three- to one-factor models were fitted, and the three-factor model showed the best fit according to the various goodness-of-fit indices: the NFI was 0.95 ( 0.87 and 0.72 for the two- and one-factor models, respectively), the TLI was 0.92 (0.82 and 0.68), the CFI was 0.96 (0.88 and 0.74), the RMSEA was 0.073 [90\% CI: 0.059 - 0.086] (0.110 [90\% CI: 0.098 0.121 ] and 0.147 [90\% CI: $0.136-0.156])$, and the BIC was -84.73 (40.34 and 311.96).

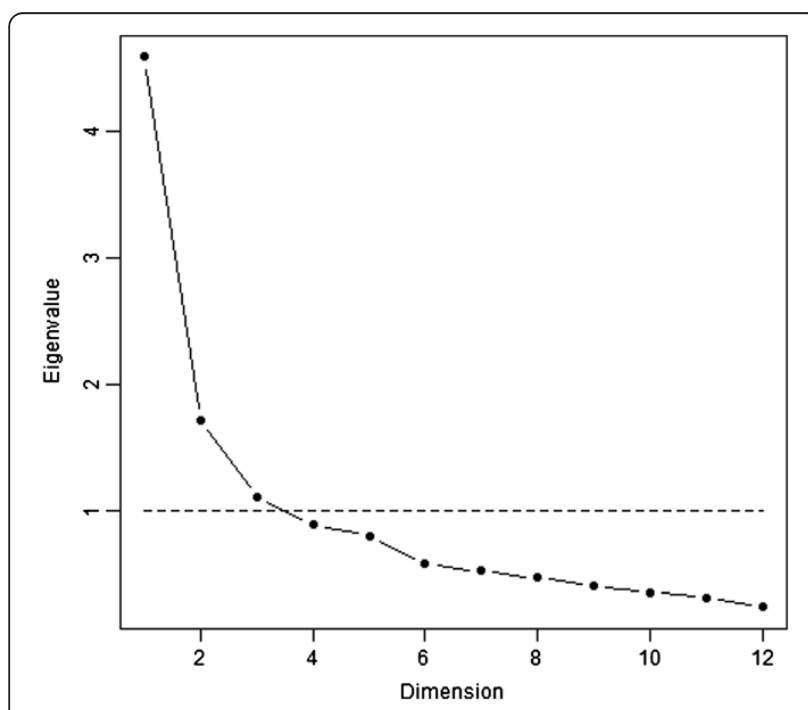

Figure 2 Scree plot of the eigenvalues obtained in the principal component analysis $(\mathrm{N}=517)$.

\section{Reliability of the scale}

Cronbach's alpha coefficient on the overall scale was 0.84 (95\% CI: [0.81 - 0.85]. The values obtained on the "ValBI", "SatBIPA" and "SatBr" sub-scales were 0.76 [0.70 - 0.80], 0.83 [0.81 - 0.85] and 0.59 [0.52 - 0.65], respectively.

The value of each inter-sub-scale correlation coefficient was lower than the corresponding Cronbach's alpha coefficients. All the items on each of the three sub-scales met both the convergent validity and discriminant validity criteria.

Scores and sub-scores, and associations with participants' characteristics

Descriptive statistics on the overall score and the various sub-scores are presented in Table 5. The mean overall score was 34.9 (sd: 7.4), and the scores on the dimensions "ValBI", "SatBIPA", "SatBr" were 9.4 (sd: 2.2), 16.5 (sd: 4.7) and 9.0 (sd: 2.5), respectively. The various subscores are presented in terms of the participants' sociodemographic and medical characteristics in Table 6. No significant associations were found to exist between the sub-scores on the BBIS and age, level of education, or living with a partner. A higher body mass index was significantly associated with a lower score on the dimensions "ValBI" and "SatBIPA", but not with the dimension "SatBr". Having a regular gynecological follow-up and performing breast self-examination were significantly associated with higher scores on each of these dimensions. Depressive symptoms were significantly associated with higher scores on "ValBI" but with lower scores on "SatBIPA" and "SatBr". No significant associations were found to exist between the scores obtained on the BBIS and carrying a BRCA1/2 mutation.

\section{Discussion}

The aim of the present study was to investigate the psychometric properties of a generic body image scale originally developed by LN Lodder [22] on a population of unaffected female $B R C A 1 / 2$ mutation carriers / non carriers. As far as we know, this is the first study in which the psychometric properties of this scale have been studied, although it has been used by the authors of epidemiological studies. First, the Body and Breast Image Scale (BBIS) turned out to have good psychometric properties for assessing both generic body image and specific breast image in unaffected French women. Secondly, the results showed that the BBIS is a threedimensional instrument. All the items in the scale should not be combined into an overall score: three scores should be calculated, based on the three dimensions "ValBI", "SatBIPA" and "SatBr" which were brought to light here. Thirdly, analysis of the associations involving the BBIS scores showed the existence of (i) no 
Table 4 Loading values obtained in the factorial analysis after varimax rotation with a three factor model $(\mathrm{N}=517)$ (loading values under .10 were not reported)

\begin{tabular}{|c|c|c|c|}
\hline & Factor1 & Factor2 & Factor3 \\
\hline Item 1: It's important to look good & 0.822 & 0.153 & \\
\hline Item 2: It's important that breasts look good & 0.701 & & 0.107 \\
\hline Item 3: Attention to one's appearance & 0.579 & 0.387 & \\
\hline Item 4: Satisfied with one's appearance when dressed & 0.203 & 0.807 & 0.145 \\
\hline Item 5: Feeling feminine & 0.223 & 0.792 & 0.205 \\
\hline Item 6: Conscious about one's appearance & 0.237 & 0.433 & 0.159 \\
\hline Item 7: Satisfied with one's appearance when undressed & & 0.644 & 0.303 \\
\hline Item 8: Difficulty in looking at one's body when undressed (R) & & 0.373 & 0.288 \\
\hline Item 9: Difficulty in touching one's breasts (R) & & & 0.368 \\
\hline Item 10: Satisfied with appearance of breasts & 0.150 & 0.297 & 0.593 \\
\hline Item 11: Breasts feel pleasant & 0.210 & 0.207 & 0.702 \\
\hline Item 12: Feeling attractive & 0.203 & 0.604 & 0.532 \\
\hline
\end{tabular}

R: Reverse coding.

associations with the respondents' socio-demographic data (age, level of education, living with a partner), (ii) no associations with $B R C A 1 / 2$ mutation carrier status, (iii) associations with the respondents' clinical characteristics (body mass index, regular gynecological follow-up, breast self-examination, depressive symptoms).

First, the BBIS showed satisfactory psychometric properties. The incomplete response rate to the BBIS was only about $9 \%$ (1.6\% to $3.9 \%$ depending on the items). In the multivariate analysis, the only variable found to be significantly associated with a lower risk of missing values was a high level of education, which is known to be a predictive factor of fewer missing values in epidemiological studies [33]. A ceiling effect was observed with the eighth and ninth items, possibly due to their negative wording [34]. The ninth item ("I had difficulty touching my breasts") showed the strongest ceiling effect, but we decided to keep it because it might be sensitive to change among carriers of a BRCA1/2 mutation, who might eventually opt for prophylactic surgery. However, this ceiling effect was not observed any longer when the various items in each dimension in which it was observed were pooled.

The consistency of the sub-scales was moderate to good. The moderately low value of the coefficient obtained on the "SatBr" dimension may have been due to the small number of items in this sub-scale. However, a Cronbach's alpha coefficient of 0.50 or more can be taken to suffice in an exploratory analysis of this kind [34]. Some items (i.e. items 12 \& 8) had similar loadings on several sub-scales. However, based on the meaning of these items and on the fact that the item convergent validity and item discriminant validity criteria were satisfied, these two items were taken to belong to the "SatBIPA" dimension.

Secondly, based on the results of an exploratory factorial analysis, the BBIS was found to be a threedimensional scale. The factor analysis and the goodnessof-fit indices confirmed this finding. Upon analyzing the three scores based on the three dimensions, it was observed that they could vary differently, depending on some respondents' characteristics, emphasizing that it was necessary to analyze each dimension independently, as they all reflected different concepts. As far as we know, LN Lodder was the first author to analyze responses to the BBIS by drawing up two scores, one on the general body image and one on the breast-related body image [22], but no statistical analysis of the dimensional structure of the scale was presented in that study. Judging from our results, Lodder's general body image

Table 5 Descriptive statistics on the overall score and the various sub-scores $(N=517)$

\begin{tabular}{cccccccc}
\hline & Mean & SD & Minimum & 1st Quartile & Median & 3rd Quartile & Maximum \\
\hline Overall score & 34.9 & 7.4 & 12 & 30 & 36 & 40 & 48 \\
Values attached to body image & 9.4 & 2.2 & 0 & 8 & 10 & 11 & 12 \\
Satisfaction with body image and perceived attractiveness & 16.5 & 4.7 & 2 & 13 & 17 & 20 & 24 \\
Satisfaction with breasts & 9.0 & 2.5 & 1 & 7 & 10 & 11 \\
\hline
\end{tabular}


Table 6 Overall score and the various sub-scores in terms of respondents' socio-demographic and medical characteristics $(\mathrm{N}=\mathbf{5 1 7})$

\begin{tabular}{|c|c|c|c|c|c|c|c|c|c|c|}
\hline & \multirow[b]{2}{*}{$\mathbf{N}$} & \multicolumn{3}{|c|}{$\begin{array}{l}\text { Values attached to } \\
\text { body image }\end{array}$} & \multicolumn{3}{|c|}{$\begin{array}{l}\text { Satisfaction with body image and } \\
\text { perceived attractiveness }\end{array}$} & \multicolumn{3}{|c|}{$\begin{array}{l}\text { Satisfaction } \\
\text { with breasts }\end{array}$} \\
\hline & & Mean & Sd & p-value & Mean & Sd & p-value & Mean & Sd & $\mathrm{p}$-value \\
\hline Age (yrs) & & & & 0.67 & & & 0.59 & & & 0.23 \\
\hline$\leq 30$ & 102 & 9.34 & 1.78 & & 16.52 & 4.89 & & 9.25 & 2.32 & \\
\hline $31-40$ & 195 & 9.23 & 2.14 & & 16.21 & 4.73 & & 8.89 & 2.53 & \\
\hline $41-50$ & 136 & 9.52 & 2.37 & & 16.65 & 4.80 & & 8.94 & 2.55 & \\
\hline$>50$ & 84 & 9.64 & 2.35 & & 16.93 & 4.28 & & 9.17 & 2.26 & \\
\hline Level of education & & & & 0.64 & & & 0.44 & & & 0.88 \\
\hline Less than high school certificate level & 111 & 9.58 & 2.66 & & 17.23 & 5.10 & & 9.10 & 2.73 & \\
\hline High school certificate & 103 & 9.44 & 2.36 & & 16.74 & 4.75 & & 9.05 & 2.36 & \\
\hline Above high school certificate level & 301 & 9.31 & 1.89 & & 16.15 & 4.51 & & 8.98 & 2.39 & \\
\hline Living with a partner & & & & 0.88 & & & 0.80 & & & 0.92 \\
\hline No & 119 & 9.38 & 2.29 & & 16.37 & 4.75 & & 9.03 & 2.36 & \\
\hline Yes & 384 & 9.41 & 2.14 & & 16.49 & 4.76 & & 9.01 & 2.50 & \\
\hline Body mass index class & & & & $<0.01$ & & & $<0.01$ & & & 0.92 \\
\hline$<18.5$ Underweight & 30 & 9.70 & 2.02 & & 19.03 & 4.24 & & 8.97 & 2.37 & \\
\hline 18.5-24.9 Normal weight & 354 & 9.49 & 2.07 & & 16.69 & 4.51 & & 9.05 & 2.43 & \\
\hline 25.0-29.9 Overweight & 97 & 9.26 & 2.12 & & 15.62 & 4.96 & & 8.90 & 2.59 & \\
\hline$\geq 30$ Obesity & 24 & 7.92 & 3.31 & & 13.21 & 5.07 & & 8.79 & 2.50 & \\
\hline Regular gynecological follow-up & & & & 0.04 & & & 0.05 & & & 0.02 \\
\hline No & 50 & 8.82 & 2.64 & & 15.28 & 4.90 & & 8.28 & 2.77 & \\
\hline Yes & 463 & 9.48 & 2.07 & & 16.67 & 4.67 & & 9.12 & 2.40 & \\
\hline Breast self-examination & & & & 0.02 & & & 0.01 & & & $<0.01$ \\
\hline No & 277 & 9.21 & 2.27 & & 16.00 & 4.69 & & 8.75 & 2.53 & \\
\hline Yes & 233 & 9.65 & 2.02 & & 17.17 & 4.66 & & 9.37 & 2.30 & \\
\hline Depressive symptoms (score CES-D $\geq 23)\left(Q_{D 15}\right)$ & & & & 0.02 & & & $<0.01$ & & & $<0.01$ \\
\hline No & 405 & 9.29 & 2.14 & & 16.93 & 4.43 & & 9.26 & 2.33 & \\
\hline Yes & 88 & 9.91 & 2.31 & & 14.82 & 5.64 & & 8.26 & 2.76 & \\
\hline BRCA1/2 mutation & & & & 0.13 & & & 0.36 & & & 0.08 \\
\hline Non carriers & 293 & 9.27 & 2.20 & & 16.34 & 4.61 & & 8.86 & 2.49 & \\
\hline Carriers & 224 & 9.56 & 2.12 & & 16.72 & 4.82 & & 9.24 & 2.39 & \\
\hline
\end{tabular}

CES-D: Center for Epidemiologic Depression Scale; $Q_{D 15}$ : questionnaire filled in 15 days after test result disclosure.

dimension actually consisted of two dimensions ("ValBI" reflecting a body image trait and "SatBIPA" reflecting a body image state) [35].

Thirdly, the results obtained upon examining the relationships with various characteristics were consistent with data previously published in the literature. No significant associations were found to exist between the scores obtained on the BBIS and the socio-demographic variables collected, including age. Since marked changes in appearance occur during adult life, especially in women, one might expect the body image to undergo similar changes. In fact, body dissatisfaction has been found to remain unchanged during the whole life span in women as the importance of women's body shape, weight, and appearance decreases. An important distinction therefore has to be made between self-assessments and the importance of the body in general [36]. The level of education was not found here to be a determinant. Some studies have shown that individuals with a higher socioeconomic status, especially women, tend to be more dissatisfied with their bodies than those with a lower status [37-39]. It has been suggested that this might be due to the role played by thinness as an indicator of social status [38]. Although the scores obtained here were not significantly associated with the level of education, they showed the existence of a tendency on 
these lines. Living with a partner was not found to be a significant determinant. It has been reported that marital status is not associated with body dissatisfaction, although low marital satisfaction was found to be significantly associated with body dissatisfaction [40-42].

We did not find any significant links between our measures and the respondents' $B R C A 1 / 2$ mutation carrier status. However, there was a trend indicating that differences may exist between BRCA1/2 mutation carriers and non-carriers as regards breast satisfaction. One might expect breast satisfaction to be lower among BRCA1/2 mutation carriers, who may feel uncomfortable about their breasts, which they may regard as a source of disease. Our results unexpectedly showed the existence of a trend whereby higher scores were obtained on the "SatBr" dimension among BRCA1/2 mutation carriers. Disclosure of positive test results was therefore not associated with a poorer breast image. It would now be worth assessing the effects of mutation carrier status and those of prophylactic surgery on $B R C A 1 / 2$ mutation carriers with time [22,23].

The present results showed the existence of significant associations between our body image scores and the respondents' clinical characteristics. The links between high BMI and poor body satisfaction have been widely documented $[13,42,43]$. The lack of associations observed here between the BMI and the "SatBr" scores was more unexpected. This finding illustrates the fact that differences can exist between body image and breast image, depending on the BMI class, and thus shows that the breast-related body image should be assessed independently.

Significant associations were found to exist between the BBIS scores obtained here and the respondents' depressive symptoms; higher scores were obtained on the dimension "ValBI" but lower scores on the dimensions "SatBIPA" and "SatBr" by women with depressive symptoms. Body image is partly based on beauty norms and the ideal body, and people assess their body partly depending on how well it matches their picture of the ideal body. Depressive symptoms are associated with low selfesteem, which can result from the existence of a large discrepancy between one's perceived body and one's ideal body. The present results confirm the existence of a gap between the ideal, imaginary body (as assessed by the importance attached to body image, "ValBI") and the perceived body ("SatBIPA" and "SatBr") in people with psychological disorders [44]. The links between body image dissatisfaction and depressive symptoms or psychological disorders have been previously documented in many clinical and non clinical contexts $[37,42,45,46]$.

One of the limitations of this study on the psychometric properties of the scale tested was that the relationships between this scale and other similar concepts were not explored. Since the data collected in the framework of the GENEPSO cohort included only one body image scale, it was not possible to assess concurrent validity criteria. However, our results on the associations between our BBIS measurements and various respondents' characteristics were consistent with data available in the literature. Another limitation of this study was the relatively low reliability of the "SatBr" subscale. However, the low value obtained in this respect, which may have been partly due to the small number of items in the subscale, was nevertheless higher than a threshold proposed for exploratory analyses [34]. The last limitation might be the non-random selection of our study population. But as the women included in this multicenter study were recruited just before the consultation at which they received their test results, our sample can be said to be a non-selected sample representative of the healthy women tested for BRCA1/2 mutations at French cancer genetic clinics.

One question which needs to be discussed is whether the results obtained here can be generalized and whether the scale presented here can be used in other contexts. This scale can obviously be used only on women, as it focuses on several aspects relating to femininity and breasts. The characteristics of our study population were compared with those of women in the French general population, based on data published by INSEE [47] (the National Institute for Statistics and Economic Science): the women in our study differed from those in the general population in that they were younger and had a higher level of education. But they resembled the women in the general population in terms of BMI and the presence of depressive symptoms. As the women's socio-demographic characteristics, contrary to their medical characteristics, were not associated with the results obtained on the BBIS, our results can presumably be generalized to French women on the whole. As far as the use of the scale in other countries is concerned, special attention should be paid to societal ideals and cultural norms, as these factors can greatly influence body perception.

\section{Conclusions}

One of the main strengths of the Breast and Body Image Scale (BBIS), a three-dimensional scale allowing to assess three components of body image in women, is that it was not drawn up with any particular pathology or predisposition to any specific disease in mind. It can therefore presumably be applied to various female populations, whether they are healthy or suffer from a specific disease. The BBIS can therefore be said to be a means of obtaining a basic generic picture of body image, to which users could add further items (organ-related items, disease-related items, etc.) when assessing body image in specific contexts. The BBIS has several potential applications. It could be used, for example, to assess the changes with time in respondents' body image in 
various contexts such as longitudinal epidemiological studies or clinical trials. In the context of $B R C A 1 / 2$ carriers, it could be used to assess the impact of prophylactic surgery (i.e. risk-reducing mastectomy and/or oophorectomy) on body image with time.

This study is the first step in the validation of the BBIS, a generic body image scale. Further research is now required to confirm the reliability of the findings obtained here by applying this tool to other populations in other contexts.

\section{Competing interests}

The authors declared that they have no competing interest.

\section{Authors' contributions}

NR performed all statistical analyses and wrote the first draft of the manuscript. CN conceived the GENEPSO cohort and supervised data collection. RG contributed to methods and interpretation of data. CJR designed the study, contributed to methods, analysis and interpretation to the data, and participated in drafting the manuscript. All the authors have read, commented and approved the final version of the manuscript.

\section{Acknowledgments}

This work was supported by Institut National du Cancer INCA RPT08011AA. All the members of the GENEPSO cohort team including Claude Adenis, Pascaline Berthet, Yves-Jean Bignon, Valérie Bonadona, Olivier Caron, Annie Chevrier, Agnès Chomprett, Odile Cohen-Haguenauer, Isabelle Coupier, Liliane Demanget, Capucine Delnatte, Hélène Dreyfus, Catherine Dugast, François Eisinger, Laurence Faivre, Marc Frenay, Jean-Pierre Fricker, Marion Gauthier-Villars, Paul Gesta, Laurence Gladieff, Christine Lasset, Michel Longy, Elisabeth Luporsi, Emmanuelle Mouret-Fourme, Tan Dat Nguyen, Claude Picard, Irwin Piot, Hagay Sobol, Dominique Stoppa-Lyonnet, Laurence VenatBouvet, Philippe Vennin, and Hélène Zattara-Cannoni.

The authors thank Roxane Fabre and Anne-Deborah Bouhnik for their statistical expertise, Ingeborg Blancquaert, Myriam Welkenhuysen and Litanja Lodder for their participation in the translation-back translation process of the BBIS, and Dr Jessica Blanc for editing the English version of the manuscript.

\section{Author details}

${ }^{1}$ INSERM, U912, SESSTIM, Marseille, France. ${ }^{2}$ IRD, U912, SESSTIM, Marseille, France. ${ }^{3}$ Aix-Marseille Université, U912, SESSTIM, Marseille, France. ${ }^{4}$ Hôpital René Huguenin, Saint-Cloud, France. ${ }^{5}$ Institut Curie, Paris, France. ${ }^{6}$ Institut Paoli-Calmettes, Marseille, France.

Received: 30 July 2012 Accepted: 5 May 2013

Published: 16 May 2013

\section{References}

1. Cash TF, Jakatdar TA, Williams EF: The Body Image Quality of Life Inventory: further validation with college men and women. Body Image 2004, 1(3):279-287.

2. Cash TF, Pruzinsky T: Body image: A handbook of theory, research, and clinical practice. New York: Guilford Press; 2002.

3. Thompson JK: The (mis)measurement of body image: ten strategies to improve assessment for applied and research purposes. Body Image 2004, 1(1):7-14.

4. Cash TF, Szymanski ML: The development and validation of the BodyImage Ideals Questionnaire. J Pers Assess 1995, 64(3):466-477.

5. Gillen MM, Lefkowitz ES: Gender and racial/ethnic differences in body image development among college students. Body Image 2012, 9(1):126-130.

6. van den Berg P, Paxton SJ, Keery H, Wall M, Guo J, Neumark-Sztainer D: Body dissatisfaction and body comparison with media images in males and females. Body Image 2007, 4(3):257-268.

7. Bresser PJ, Seynaeve C, Van Gool AR, Brekelmans CT, Meijers-Heijboer H, van Geel AN, Menke-Pluijmers MB, Duivenvoorden HJ, Klijn JG, Tibben A: Satisfaction with prophylactic mastectomy and breast reconstruction in genetically predisposed women. Plast Reconstr Surg 2006, 117(6):1675-1682. discussion 1683-1684

8. Frost MH, Slezak JM, Tran NV, Williams Cl, Johnson JL, Woods JE, Petty PM, Donohue JH, Grant CS, Sloan JA, Sellers TA, Hartmann LC: Satisfaction after contralateral prophylactic mastectomy: the significance of mastectomy type, reconstructive complications, and body appearance. J Clin Oncol 2005, 23(31):7849-7856.

9. Coriddi M, Koltz PF, Gusenoff JA: Reduction mammaplasty, obesity, and massive weight loss: temporal relationships of satisfaction with breast contour. Plast Reconstr Surg 2011, 128(3):643-650.

10. Sarwer DB, Crerand CE: Body image and cosmetic medical treatments. Body Image 2004, 1(1):99-111.

11. Carraca EV, Silva MN, Markland D, Vieira PN, Minderico CS, Sardinha LB, Teixeira PJ: Body image change and improved eating self-regulation in a weight management intervention in women. Int J Behav Nutr Phys Act 2011, 8:75

12. Palmeira AL, Branco TL, Martins SC, Minderico CS, Silva MN, Vieira PN, Barata $J T$, Serpa SO, Sardinha LB, Teixeira PJ: Change in body image and psychological well-being during behavioral obesity treatment: Associations with weight loss and maintenance. Body Image 2010, 7(3):187-193.

13. Schwartz MB, Brownell KD: Obesity and body image. Body Image 2004, $1(1): 43-56$.

14. Levine MP, Piran N: The role of body image in the prevention of eating disorders. Body Image 2004, 1(1):57-70.

15. Tury F, Gulec $H$, Kohls E: Assessment methods for eating disorders and body image disorders. J Psychosom Res 2010, 69(6):601-611.

16. Hopwood P: The assessment of body image in cancer patients. Eur J Cancer 1993, 29A(2):276-281.

17. Hopwood P, Fletcher I, Lee A, Al Ghazal S: A body image scale for use with cancer patients. Eur J Cancer 2001, 37(2):189-197.

18. Martinez SM, Kemper CA, Diamond C, Wagner G: Body image in patients with HIV/AIDS: assessment of a new psychometric measure and its medical correlates. AIDS Patient Care STDS 2005, 19(3):150-156.

19. Avalos L, Tylka TL, Wood-Barcalow N: The Body Appreciation Scale: development and psychometric evaluation. Body Image 2005, 2(3):285-297.

20. Cash TF, Phillips KA, Santos MT, Hrabosky J: Measuring "negative body image": validation of the Body Image Disturbance Questionnaire in a nonclinical population. Body Image 2004, 1(4):363-372.

21. Lichtenthal WG, Cruess DG, Clark VL, Ming ME: Investment in body image among patients diagnosed with or at risk for malignant melanoma. Body Image 2005, 2(1):41-51.

22. Lodder LN, Frets PG, Trijsburg RW, Meijers-Heijboer EJ, Klijn JG, Seynaeve C, van Geel AN, Tilanus MM, Bartels CC, Verhoog LC, Brekelmans CT, Burger CW, Niermeijer MF: One year follow-up of women opting for presymptomatic testing for BRCA1 and BRCA2: emotional impact of the test outcome and decisions on risk management (surveillance or prophylactic surgery). Breast Cancer Res Treat 2002, 73(2):97-112.

23. van Oostrom I, Meijers-Heijboer H, Lodder LN, Duivenvoorden HJ, van Gool AR, Seynaeve C, van der Meer CA, Klijn JG, van Geel BN, Burger CW, Wladimiroff JW, Tibben A: Long-term psychological impact of carrying a BRCA1/2 mutation and prophylactic surgery: a 5-year follow-up study. J Clin Oncol 2003, 21(20):3867-3874.

24. Blackwood MA, Weber BL: BRCA1 and BRCA2: from molecular genetics to clinical medicine. J Clin Oncol 1998, 16(5):1969-1977.

25. Ford D, Easton DF, Stratton M, Narod S, Goldgar D, Devilee P, Bishop DT, Weber B, Lenoir G, Chang-Claude J, Sobol H, Teare MD, Struewing J, Arason A, Scherneck S, Peto J, Rebbeck TR, Tonin P, Neuhausen S, Barkardottir R, Eyjjord J, Lynch H, Ponder BA, Gayther SA, Zeleda-Hedman M: Genetic heterogeneity and penetrance analysis of the BRCA1 and BRCA2 genes in breast cancer families. The Breast Cancer Linkage Consortium. Am J Hum Genet 1998, 62(3):676-689.

26. Esplen MJ, Stuckless N, Hunter J, Liede A, Metcalfe K, Glendon G, Narod S, Butler K, Scott J, Irwin E: The BRCA Self-Concept Scale: a new instrument to measure self-concept in BRCA1/2 mutation carriers. Psychooncology 2009, 18(11):1216-1229.

27. Julian-Reynier C, Bouhnik AD, Mouret-Fourme E, Gauthier-Villars M, Berthet P, Lasset C, Fricker JP, Caron O, Gesta P, Luporsi E, Faivre L, Longy M, Gladieff L, Frenay M, Dreyfus H, Sobol H, Vennin P, Nogues C: Time to prophylactic surgery in BRCA1/2 carriers depends on psychological and other characteristics. Genet Med 2010, 12(12):801-807. 
28. Fuhrer R, Rouillon F: The French version of the Center for Epidemiologic Studies-Depression Scale. Psychiatr Psychobiol 1989, 4(3):163-166.

29. Radloff $L$ : The CES-D scale: a self report depression scale for research in the general population. Appl Psychol Meas 1977, 1:385-401.

30. Guillemin F, Bombardier C, Beaton D: Cross-cultural adaptation of healthrelated quality of life measures: literature review and proposed guidelines. J Clin Epidemiol 1993, 46(12):1417-1432.

31. Bentler PM: Comparative fit indexes in structural models. Psychol Bull 1990, 107(2):238-246.

32. Ware JE Jr, Gandek B: Methods for testing data quality, scaling assumptions, and reliability: the IQOLA project approach. International Quality of Life Assessment. J Clin Epidemiol 1998, 51(11):945-952.

33. Peyre $\mathrm{H}$, Coste J, Leplege A: Identifying type and determinants of missing items in quality of life questionnaires: application to the SF-36 French version of the 2003 Decennial Health Survey. Health Qual Life Outcomes 2010, 8:16.

34. Streiner D, Norman G: Health Measurement Scales. Oxford: New York; 2000.

35. Colautti LA, Fuller-Tyszkiewicz M, Skouteris H, McCabe M, Blackburn S, Wyett E: Accounting for fluctuations in body dissatisfaction. Body Image 2011, 8(4):315-321.

36. Tiggemann M: Body image across the adult life span: stability and change. Body Image 2004, 1(1):29-41.

37. Gavin AR, Simon GE, Ludman EJ: The association between obesity, depression, and educational attainment in women: the mediating role of body image dissatisfaction. J Psychosom Res 2010, 69(6):573-581.

38. McLaren L, Kuh D: Women's body dissatisfaction, social class, and social mobility. Soc Sci Med 2004, 58(9):1575-1584.

39. Wardle J, Griffith J: Socioeconomic status and weight control practices in British adults. J Epidemiol Community Health 2001, 55(3):185-190.

40. Friedman MA, Dixon AE, Brownell KD, Whisman MA, Wilfley DE: Marital status, marital satisfaction, and body image dissatisfaction. Int J Eat Disord 1999, 26(1):81-85.

41. Luo Y, Parish WL, Laumann EO: A population-based study of body image concerns among urban Chinese adults. Body Image 2005, 2(4):333-345.

42. Santos Silva DA, Nahas MV, de Sousa TF, Del Duca GF, Peres KG: Prevalence and associated factors with body image dissatisfaction among adults in southern Brazil: a population-based study. Body Image 2011, 8(4):427-431.

43. Annis NM, Cash TF, Hrabosky J: Body image and psychosocial differences among stable average weight, currently overweight, and formerly overweight women: the role of stigmatizing experiences. Body Image 2004, 1(2):155-167.

44. Woodman T, Steer R: Body self-discrepancies and women's social physique anxiety: the moderating role of the feared body. $\mathrm{Br} J$ Psycho 2011, 102(2):147-160.

45. Moreira H, Canavarro MC: A longitudinal study about the body image and psychosocial adjustment of breast cancer patients during the course of the disease. Eur J Oncol Nurs 2010, 14(4):263-270.

46. Sharpe L, Patel D, Clarke S: The relationship between body image disturbance and distress in colorectal cancer patients with and without stomas. J Psychosom Res 2011, 70(5):395-402.

47. INSEE. Institut national de la statistique et des études économiques: [http://www.insee.fr]

doi:10.1186/1472-6874-13-24

Cite this article as: Resseguier et al:: Psychometric properties of a French version of a Dutch scale for assessing breast and body image (BBIS) in healthy women. BMC Women's Health 2013 13:24.

\section{Submit your next manuscript to BioMed Central and take full advantage of:}

- Convenient online submission

- Thorough peer review

- No space constraints or color figure charges

- Immediate publication on acceptance

- Inclusion in PubMed, CAS, Scopus and Google Scholar

- Research which is freely available for redistribution

Submit your manuscript at www.biomedcentral.com/submit
C Biomed Central 